\title{
G $\alpha$ q-Protein Carboxyl Terminus Imitation Polypeptide GCIP-27 Attenuates Proliferation of Vascular Smooth Muscle Cells and Vascular Remodeling in Spontaneously Hypertensive Rats
}

\author{
Hai-Gang Zhang, Yi-Qun Cheng, Ya Liu, Jian-Zhi Zhou, Yi Jia, Xiu-Qin Wang, and Xiao-Hui Li* \\ Institute of Materia Medica and Department of Pharmaceutics, College of Pharmacy, Third Military Medical University; \\ Chongqing 400038, China. Received December 22, 2010; accepted June 4, 2011; published online July 7, 2011
}

\begin{abstract}
Gq-protein is located at the convergent point in signal transduction pathways leading to vascular remodeling. The carboxyl terminus of $\mathrm{G} \alpha$-subunit plays a vital role in G-protein-receptor interaction. The present study was designed to explore the effects of a synthetic G $\alpha$ q carboxyl terminus imitation peptide, namely GCIP-27, on vascular smooth muscle cells (VSMC) in vitro and vascular remodeling in spontaneous hypertensive rats (SHR). Hyperplasia and hypertrophy of VSMC wre determined by 3-(4,5-dimethylthiazol-2-yl)-2,5-diphenyltetrazolium bromide (MTT) assay, $\left[{ }^{3} \mathrm{H}\right]$-thymidine and $\left[{ }^{3} \mathrm{H}\right]$-leucine incorporation, and $\left[\mathrm{Ca}^{2+}\right]_{\mathrm{i}}$ was measured with Fluo3/AM staining. Systolic blood pressure (SBP), the ratio of media thickness to lumen diameter (MT/LD) of aorta, collagen content, and phospholipase $C$ activity in aorta were measured in SHR. GCIP-27 (3-100 $\mu \mathrm{g} / \mathrm{I})$ significantly decreased proliferation activity, protein content, incorporation of $\left[{ }^{3} \mathrm{H}\right]$-thymidine and $\left[{ }^{3} \mathrm{H}\right]-\mathrm{leucine}$, and $\left[\mathrm{Ca}^{2+}\right]_{\mathrm{i}}$ level in VSMC. SBP, MT/LD, collagen content, and phospholipase $C$ activity in aorta of SHR were decreased significantly in GCIP-27 $(7,20,60 \mu \mathrm{g} / \mathrm{kg})$-treated groups and losartan $(6 \mathrm{mg} / \mathrm{kg})$ group compared with vehicle group. In conclusion, GCIP-27 could inhibit vascular remodeling effectively in vitro and in vivo.
\end{abstract}

Key words polypeptide drug; Gq protein; hypertension; vascular remodeling; vascular smooth muscle cell

Vascular hypertrophy and remodeling are adaptive structural changes in response to sustained increases in arterial pressure or altered shear stress. ${ }^{1)}$ These structural changes, which occur in various clinical disorders including hypertension, atherosclerosis, and restenosis after balloon angioplasty not only play critical roles in the pathogenic mechanisms of these conditions but are also key targets for treating such diseases. $^{2)}$

Accumulating evidence indicates that various Gq proteincoupled receptor ligands such as noradrenaline (NA), angiotensin II (Ang II), endothelin-1 (ET-1), neuropeptide Y (NPY), and vasopressin can trigger hypertrophic responses in cultured vascular smooth muscle cells (VSMC) and vascular remodeling in vivo. ${ }^{1-6)}$ These neurohumoral factors induce vascular hypertrophy and remodeling through hemodynamic and direct non-hemodynamic pathways that are related closely to $\mathrm{Gq}$ signaling. These findings are consistent with the conclusion that Gq protein and its downstream molecules play vital roles in signal transduction pathway inducing vascular remodeling; Gq protein is thought to locate at the convergent point. Although some antihypertensive agents such as angiotensin-converting enzyme inhibitors (ACEIs) and angiotensin receptor blocking agents (ARBs), can alleviate vascular hypertrophy and remodeling to some extent, the effects of these drugs with a single target are limited due to compensatory secretion of other $\mathrm{Gq}$ protein-coupled receptor ligands. ${ }^{7}$ Theoretically, targeting the Gq signaling pathway may have more satisfactory effect on vascular remodeling therapy. In the heterotrimetic $G$ protein, the carboxyl terminus of $\alpha$-subunit is surface exposed and easily accessible for contacting the receptor protein, so the $\mathrm{C}$-terminal portion of $\mathrm{G} \alpha$ is critical for the specificity of G-protein-coupled receptor. $^{8-10)}$ Therefore inhibition of G $\alpha$ q signaling may be an approach to prevent vascular remodeling from overloaded pressure and other pathological stimuli.

$\mathrm{G} \alpha \mathrm{q}$ protein carboxyl terminus imitation polypeptide
(GCIP), a peptide cloned and constructed in our laboratory, is able to inhibit cardiomyocyte hypertrophy induced by NA in vitro. ${ }^{11)}$ GCIP-27, the optimized form of GCIP, could prevent hypertrophic responses in cultured rat cardiomyocytes induced by NA or Ang II, inhibited left ventricular hypertrophy induced by NA in mice and rats and that induced by suprarenal abdominal aortic stenosis in rats, as well as right ventricular hypertrophy induced by monocrotaline. ${ }^{12-14)}$ However, little is known about the effect of GCIP-27 on vascular remodeling. Because the pathophysiological process of vascular remodeling is quite complex and may include unique elements not observed in cardiac hypertrophy, it is necessary to characterize the effect of GCIP-27 on vascular remodeling. Therefore the present study was designed to explore the potential effects of GCIP-27 on proliferation of VSMC and vascular remodeling in spontaneously hypertensive rats (SHR).

\section{MATERIALS AND METHODS}

Animals Male SHR and Wistar-Kyoto (WKY) rats (12 weeks old; weighing $200-250 \mathrm{~g}$ ) were purchased from the Experimental Animals Center of the Third Military Medical University (Chongqing, China). Rats were housed under conditions of controlled temperature $\left(23-25^{\circ} \mathrm{C}\right)$ and humidity (50-60\%), 12-h light-dark cycle, and air exhaust cycle $(15 \mathrm{~min} / \mathrm{h})$. Rats were fed standard food and water ad libitum. Experiments were performed after gaining formal approval by the Institutional Ethical Committee for Research on Animals.

Treatments In the in vivo experiments, SHR $(n=25)$ were randomly divided into 5 groups $(n=5$ in each): vehicle group, losartan-treated group, and three GCIP-27-treated groups. In addition, five WKY rats were used as normal controls. SHR in the GCIP-27-treated groups were injected intraperitoneally (i.p.) with 7, 20, or $60 \mu \mathrm{g} / \mathrm{kg}$ GCIP-27 (syn- 
thesised by Scilight Biotechnology, Beijing, China; purity $>98 \%$ ) dissolved in normal saline $(3 \mathrm{ml} / \mathrm{kg})$ twice daily; rats in the vehicle group were injected with the same volume of normal saline, and those in the losartan treated group were administered $6 \mathrm{mg} / \mathrm{kg}$ losartan (Sigma Chemical, St. Louis, MO, U.S.A.) intragastrically once daily. WKY rats were administered normal saline $(3 \mathrm{ml} / \mathrm{kg})$ intragastrically. All animals were treated for 8 weeks (from 14 to 21 weeks of age) and weighed weekly to adjust the doses accordingly.

Cell Culture VSMC from SHR were isolated and characterized as previously described. ${ }^{15)}$ Briefly, primary cultured rat VSMC were obtained by modified tissue-piece inoculation of the aortas of rats. Cells were cultured in Dulbecco's modified Eagle's medium (DMEM; Gibco-BRL, Gaithersburg, MD, U.S.A.) containing 10\% fetal bovine serum (FBS, Hyclone, Logan, UT, U.S.A.) at $37^{\circ} \mathrm{C}$ in a $5 \% \mathrm{CO}_{2}$ humidified incubator. Early passaged (4th to 8th passages) cells were used for experiments. Cells were rendered quiescent by serum deprivation for $48 \mathrm{~h}$ before experimentation.

Proliferation of VMSC After being cultured in serumfree medium for $48 \mathrm{~h}$, VSMC from SHR were washed twice with D-Hanks' balanced salt solution at $37^{\circ} \mathrm{C}$. Washed cells were seeded on a 96-well plate at $1 \times 10^{4}$ cells/well and incubated for $24 \mathrm{~h}$ in DMEM containing $1 \% \mathrm{FBS}$ and $10^{-7} \mathrm{~mol} / 1$ Ang II (Sigma Chemical, St. Louis, MO, U.S.A.) to induce hypertrophic response. ${ }^{16)}$ Different concentrations of GCIP$27(1,3,10,30,100 \mu \mathrm{g} / \mathrm{l})$ were added to observe its effects. The same volume of phosphate buffered saline (PBS) and losartan $\left(10^{-5} \mathrm{~mol} / \mathrm{l}\right)$ was used as normal and positive control, respectively. Thereafter, viable cells were assayed by 3 (4,5-dimethylthiazol-2-yl)-2,5-diphenyltetrazolium bromide (MTT) method. NIH/3T3 cells (China Center for Typical Culture Collection; Wuhan, China) were used as controls to test the potential toxicity of GCIP-27.

Protein Content After being cultured in medium containing the various reagents described, VSMC were washed with PBS then treated with 5\% trichloroacetic acid (TCA) at $4{ }^{\circ} \mathrm{C}$ for $1 \mathrm{~h}$ to precipitate protein. The precipitates were dissolved in $\mathrm{NaOH}(0.1 \mathrm{~mol} / \mathrm{l})$. The protein content was measured according to the method of Lowry et al. ${ }^{17)}$ using bovine serum albumin as standard.

$\left[{ }^{3} \mathbf{H}\right]$-Thymidine Incorporation DNA synthesis was evaluated by measuring incorporation of $\left[{ }^{3} \mathrm{H}\right]$-thymidine. ${ }^{18)}$ Washed cells were seeded on a 96-well plate at $5 \times 10^{6}$ cells/well and incubated in DMEM containing 10\% FBS for $24 \mathrm{~h}$. Then, the cells were rendered quiescent for $48 \mathrm{~h}$ and stimulated as above for $24 \mathrm{~h}$ in the absence or presence of different concentrations of GCIP-27 $(1,3,10,30,100 \mu \mathrm{g} / 1)$. One $\mu \mathrm{Ci} / \mathrm{ml}$ of $\left[{ }^{3} \mathrm{H}\right]$-thymidine was added to each well for the last $12 \mathrm{~h}$ of experimental periods. The radioactivity incorporated into DNA was counted by $\beta$-plate counter (LKB Wallac 1217 Betaplate, Sweden).

$\left[{ }^{3} \mathbf{H}\right]$-Leucine Incorporation The rate of protein synthesis was measured by $\left[{ }^{3} \mathrm{H}\right]$-leucine incorporation method, as described previously. ${ }^{19)}$ Quiescent VSMC in 96-well plates were stimulated as above for $24 \mathrm{~h}$ in the absence or presence of the different concentrations of GCIP-27. One $\mu \mathrm{Ci} / \mathrm{ml}$ of $\left[{ }^{3} \mathrm{H}\right]$-leucine was added at the same time as GCIP-27. The radioactivity incorporated into proteins was determined as above.

Intracellular $\mathrm{Ca}^{2+}$ Concentration The experiment was carried out at room temperature in a darkroom. Intracellular free $\mathrm{Ca}^{2+}$ concentration $\left(\left[\mathrm{Ca}^{2+}\right]_{\mathrm{i}}\right)$ in VSMC was monitored by fluorescent $\mathrm{Ca}^{2+}$ indicator, fluorescent dye fluo3-acetoxymethyl ester (Fluo-3/AM; Biotum, Hayward, CA, U.S.A.). ${ }^{20)}$ In brief, cells growing in a special $35-\mathrm{mm}$ culture dish were loaded with Fluo-3/AM $10 \mu \mathrm{mol} / 1$ in KrebsRinger solution containing $0.05 \%$ pluronic acid at $37^{\circ} \mathrm{C}$ for $45 \mathrm{~min}$. After being washed twice with Krebs-Ringer solution to remove unhydrolyzed indicator, cells were stimulated with $1 \% \mathrm{FBS}$ and $0.1 \mu \mathrm{mol} / 1 \mathrm{Ang}$ II for $30 \mathrm{~min}$ in the absence or presence of different concentrations of GCIP-27 (1, $3,10,30,100 \mu \mathrm{g} / 1)$. Fluorescence in cells was measured by confocal microscope (TCS-SP5, Leica, Heidelberg, Germany). Changes of $\left[\mathrm{Ca}^{2+}\right]_{i}$ were detected as fluorescence intensity (FI).

Blood Pressure Measurement For experiments involving indirect recording of blood pressure, rats were prewarmed at $38^{\circ} \mathrm{C}$ for $15 \mathrm{~min}$. Systolic blood pressure (SBP) was recorded indirectly by standard tail-cuff technique with a pulse transducer (BP recorder, ML-126; PowerLab; ADInstruments, Castle Hill, NSW, Australia). ${ }^{12)}$ Rats were acclimated to the restraining cages and tail-cuff apparatus for $7 \mathrm{~d}$ before SBP was determined. Measurement of parameters was performed before the start of the treatment protocol and after $2,4,6$, and 8 week's treatment. Measurements were made in triplicate for each animal and the average served as the SBP value.

Morphological Examination After treatment for 8 weeks, all rats were killed by decapitation. Upper thoracic aorta tissue was sliced into 3-mm sections, immersion-fixed in $10 \%$ neutral-buffered formalin, embedded in paraffin, sectioned at $5 \mu \mathrm{m}$ and stained with haematoxylin-eosin. Vessel wall dimensions were measured by computer-assisted image analysis system (Motic Images Advanced 3.0; GENEQ, Montreal, Canada). The media thickness (MT) and lumen diameter (LD) of aorta were recorded and the ratio of MT/LD was calculated.

Tissue samples from the aortic arch were cut into $1-\mathrm{mm}^{3}$ pieces and fixed in $2.5 \%$ glutaraldehyde prior to examination of its ultrastructure under a transmission electron microscope.

Collagen Content Collagen content in the aorta was evaluated by determining hydroxyproline. ${ }^{21,22)}$ Briefly, the homogenized sample of aorta tissue was hydrolysed in $6 \mathrm{~mol} / \mathrm{l} \mathrm{HCl}$ and the hydroxyproline concentration determined by a hydroxyproline assay kit (Jiancheng Biological Engineering Research Institute, Nanjing, China) according to the manufacturer's instructions. Hydroxyproline (Sigma Chemical) was used as standard. The hydroxyproline concentration was used to determine collagen content as follows:

collagen content $(\mu \mathrm{g} / \mathrm{mg}$ protein $)=$ hydroxyproline content $\times 7.46$

Phospholipase C Activity Membrane protein was prepared as described previously. ${ }^{23)}$ Inositol phosphate formation was evaluated as an index of phospholipase C (PLC) activity, as described by Schnabel et al. ${ }^{24)}$

Statistical Analysis Results are presented as mean \pm S.E.M. One-way analysis of variance (ANOVA) and Tukey post hoc test were used for all analyses; $p<0.05$ was considered significant. All analyses were performed with SPSS 13.0 software. 
Table 1. Effect of GCIP-27 on Proliferation Profile and Intracellular Calcium Concentration $\left(\left[\mathrm{Ca}^{2+}\right]_{\mathrm{i}}\right.$ ) of Vascular Smooth Muscle Cells from Spontaneously Hypertensive Rats (SHR)

\begin{tabular}{|c|c|c|c|c|}
\hline & $\begin{array}{l}\text { Protein } \\
\text { content } \\
(\mu \mathrm{g})\end{array}$ & $\begin{array}{c}{\left[{ }^{3} \mathrm{H}\right] \text {-Thymidine }} \\
\text { incorporation } \\
(\mathrm{Bq})\end{array}$ & $\begin{array}{l}{\left[{ }^{3} \mathrm{H}\right] \text {-Leucine }} \\
\text { incorporation } \\
(\mathrm{Bq})\end{array}$ & $\begin{array}{l}{\left[\mathrm{Ca}^{2+}\right]_{\mathrm{i}}} \\
(\mathrm{FI})\end{array}$ \\
\hline Control & $64.67 \pm 1.90$ & $112 \pm 6.6$ & $30 \pm 1.4$ & $54 \pm 2.8$ \\
\hline Vehicle & $88.51 \pm 2.27 * *$ & * $\quad 203 \pm 10.3 * *$ & $49 \pm 3.1 * *$ & $86 \pm 3.8 * *$ \\
\hline $\begin{array}{l}\text { Losartan } \\
\qquad\left(10^{-5} \mathrm{~mol} / \mathrm{l}\right)\end{array}$ & $68.83 \pm 1.95^{\ddagger}$ & $135 \pm 5.3^{\ddagger}$ & $34 \pm 2.2^{\ddagger}$ & $60 \pm 3.4^{\ddagger}$ \\
\hline \multicolumn{5}{|l|}{ GCIP-27 } \\
\hline $1 \mu \mathrm{g} / 1$ & $83.5 \pm 3.19^{\S \S}$ & $178 \pm 8.8^{\ddagger}, \S$ & $42 \pm 2.7^{\S}$ & $80 \pm 3.2^{\S \S}$ \\
\hline $3 \mu \mathrm{g} / 1$ & $78.08 \pm 3.05^{\dagger, \S}$ & $158 \pm 7.8^{\ddagger, \S}$ & $39 \pm 1.9^{\dagger}$ & $63 \pm 2.5^{\ddagger}$ \\
\hline $10 \mu \mathrm{g} / 1$ & $75.63 \pm 3.26^{\dagger}$ & $145 \pm 8.1^{\ddagger}$ & $36 \pm 2.1^{\ddagger}$ & $55 \pm 3.0^{\ddagger}$ \\
\hline $30 \mu \mathrm{g} / 1$ & $65.14 \pm 2.18^{\ddagger}$ & $132 \pm 6.9^{*}$ & $32 \pm 1.9$ & $45 \pm 2.5^{\ddagger}, \S \S$ \\
\hline $100 \mu \mathrm{g} / 1$ & $60.04 \pm 2.83^{\ddagger}, 8$ & $122 \pm 7.2^{\ddagger}$ & $29 \pm 1.7^{\ddagger}$ & $43 \pm 2.1^{\ddagger}, \S \S$ \\
\hline
\end{tabular}

FI, $\mathrm{Ca}^{2+}$ fluorescence intensity. Cultured vascular smooth muscle cells were stimulated with $10^{-7} \mathrm{~mol} / 1$ angiotensin II or normal saline (control) and treated with vehicle, losartan, or GCIP-27. Data are presented as mean \pm S.E.M. $\left(n=12\right.$ for $\left[\mathrm{Ca}^{2+}\right], n=5$ for others). ${ }^{*} p<0.01 v s$. control group; $\dagger p<0.05, \star p<0.01 v s$. vehicle group; $\S p<0.05$, $\S \S p<0.01 v s$. losartan group (one-way analysis of variance).

\section{RESULTS}

Proliferation and Protein Content in VSMC The proliferation activity, protein content, and $\left[{ }^{3} \mathrm{H}\right]$-thymidine and $\left[{ }^{3} \mathrm{H}\right]$-leucine incorporation in VSMC from SHR were significantly higher than those from WKY. After $24 \mathrm{~h}$ of treatment, GCIP-27 at concentrations $3-100 \mu \mathrm{g} / 1$ pronouncedly decreased the protein content and $\left[{ }^{3} \mathrm{H}\right]$-thymidine and $\left[{ }^{3} \mathrm{H}\right]$ leucine incorporation based on the no treatment option $(p<0.05$ and $<0.01)$ (Table 1$)$. GCIP-27 had no significant influence on proliferation activity of 3T3 cells, while it decreased the MTT value of VSMC markedly (Fig. 1). Simultaneously, losartan decreased all the parameters of VSMC mentioned above significantly compared with those in the vehicle group.

Intracellular $\mathrm{Ca}^{2+}$ Concentration in VSMC After incubation of VSMC with Ang II $\left(10^{-7} \mathrm{~mol} / \mathrm{l}\right)$, the intensity of $\left[\mathrm{Ca}^{2+}\right]_{\mathrm{i}}$ fluorescence increased significantly by $59.3 \%$ $(p<0.01)$. GCIP-27 (3, 10, 30, $100 \mu \mathrm{g} / 1)$ and losartan markedly attenuated the intensity of the $\left[\mathrm{Ca}^{2+}\right]_{\mathrm{i}}$ signal compared with that in the vehicle group $(p<0.01)$ (Table 1$)$.

Systolic Blood Pressure SBP of SHR was 177士 $3.3 \mathrm{mmHg}$ before treatment, which was much higher than that of WKY rats $(130 \pm 4.3 \mathrm{mmHg} ; p<0.01)$ (Fig. 2). During the eight-week treatment period, SBP of WKY rats remained stable, whereas that of SHR in the vehicle group increased continuously. After treatment with losartan or GCIP-27 (7, $20,60 \mu \mathrm{g} / \mathrm{kg}$ ), SBP decreased significantly compared with vehicle group. However, the degree to which SBP was decreased in the GCIP-27 groups was less than that in the losartan-treated group. After 8 weeks' treatment, SBP was decreased $30.1 \%$ in losartan-treated group compared with the vehicle group. At the same time, it was decreased $11.4 \%$, $12.5 \%$, and $18.6 \%$ in GCIP-27 $(7,20,60 \mu \mathrm{g} / \mathrm{kg})$-treated groups, respectively.

Vascular Remodeling As shown in Fig. 3a, the thickness of the aorta media and the ratio of MT/LD in the vehicle group increased markedly by comparison with WKY rats. After the rats had been treated with losartan or GCIP-27 (7, $20,60 \mu \mathrm{g} / \mathrm{kg})$, media thickness and MT/LD ratios were lower
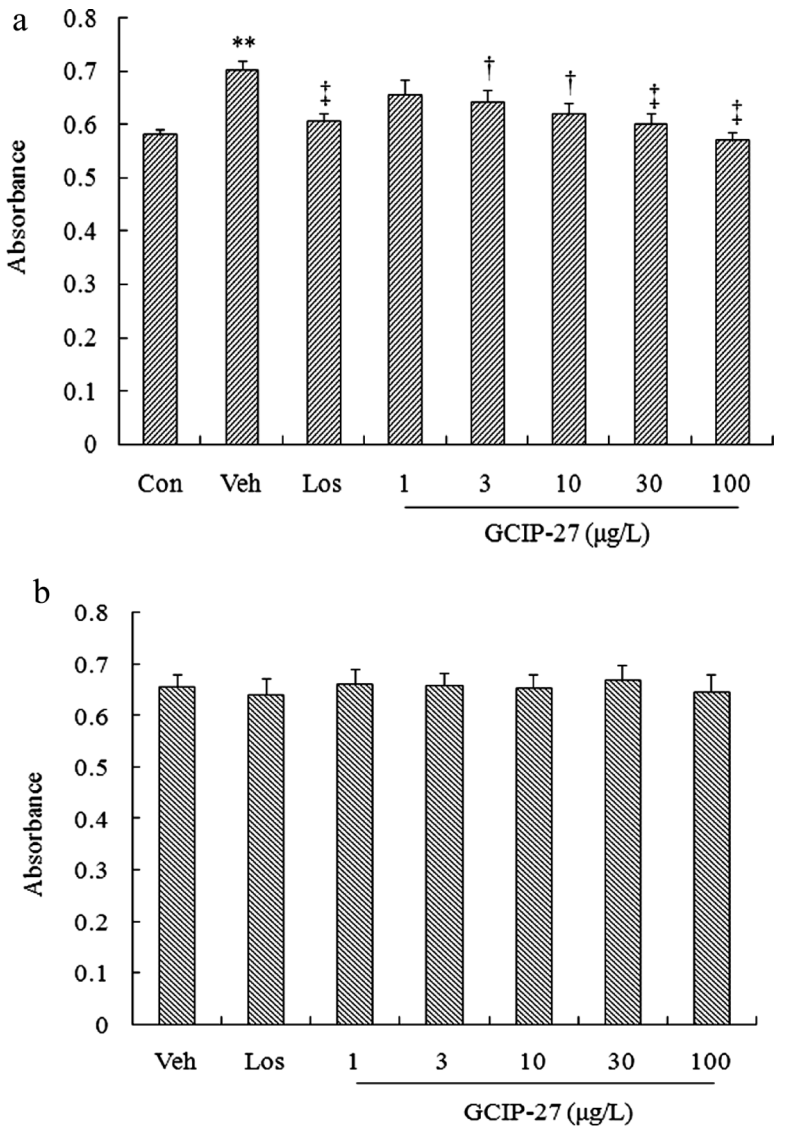

Fig. 1. Effect of GCIP-27 on Proliferation Activity of 3T3 Cells and Vascular Smooth Muscle Cells (VSMC) from Spontaneously Hypertensive Rats

(a) Cultured VSMC were stimulated with $0.1 \mu \mathrm{mol} / 1$ angiotensin II (Ang II) or normal saline (control, Con) and treated with vehicle (Veh), losartan (Los), or GCIP-27 (1, $3,10,30,100 \mu \mathrm{g} / 1$ ), respectively. (b) $3 \mathrm{~T} 3$ cells were treated as VSMC except for stimulated with Ang II. Data are presented as mean \pm S.E.M. $(n=5)$. $* * p<0.01$ vs. Con group; $\uparrow p<0.05, \ddagger p<0.01 v s$. Veh group (one-way analysis of variance).

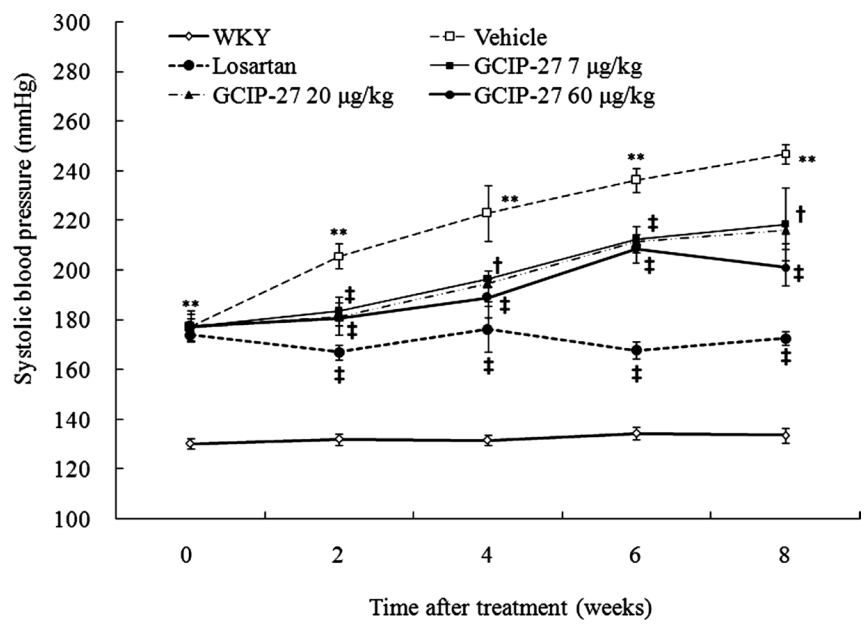

Fig. 2. Effect of GCIP-27 on Systolic Blood Pressure (SBP) in Spontaneously Hypertensive Rats (SHR)

Rats were peritoneally injected with vehicle (Veh), GCIP-27 $(7,20,60 \mu \mathrm{g} / \mathrm{kg})$, or intragastrically administered with $6 \mathrm{mg} / \mathrm{kg}$ losartan (Los). SBP was recorded indirectly by standard tail-cuff technique. Data are mean \pm S.E.M. $(n=5)$. Wistar-Kyoto $($ WKY) rats were used as normotensive control. $* * p<0.01 v s$. WKY group; $\dagger p<0.05, \ddagger p<0.01 v s$. Veh group (one-way analysis of variance).

than that of untreated SHR. MT/LD ratio reduced by $13.9 \%$ in losartan group compared with the vehicle group; while it reduced $6.9 \%, 8.3 \%$, and $13.9 \%$ in GCIP-27 (7, 20, 
a

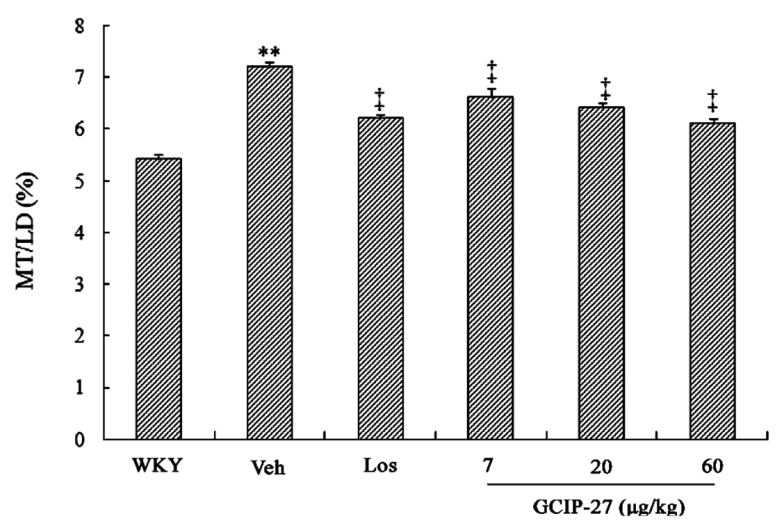

b

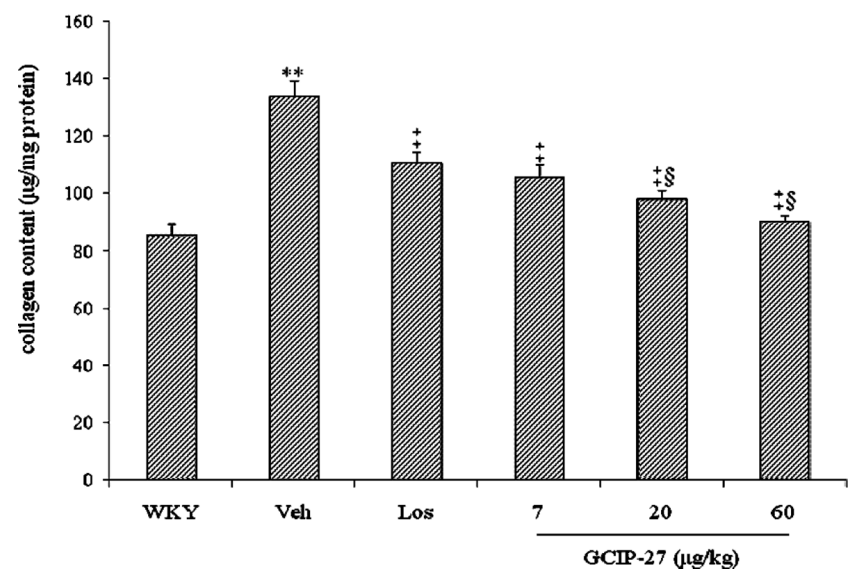

Fig. 3. Effects of GCIP-27 on Remodeling of Aorta in Spontaneously Hypertensive Rats

(a) Ratio of media thickness (MT) to lumen diameter (LD) of aorta recorded under a light microscope. (b) Aortic collagen content. Data are the mean \pm S.E.M. $(n=5)$. Wis tar-Kyoto (WKY) rats were used as normotensive control. $* * p<0.01 v s$. WKY group; $\ddagger p<0.01 v s$. Veh group; $\S p<0.01 v s$. Los group (one-way analysis of variance).

\section{$60 \mu \mathrm{g} / \mathrm{kg}$ )-treated groups, respectively.}

Collagen content in the GCIP-27 $(7,20,60 \mu \mathrm{g} / \mathrm{kg})$ and losartan-treated groups was significantly decreased compared with that in the vehicle-treated group $(p<0.01)$ (Fig. 3b). However, the magnitude of the decrease in collagen content produced by losartan $(17.1 \%)$ was less than that seen for the 7, 20 and $60 \mu \mathrm{g} / \mathrm{kg}$ GCIP-27-treated groups (21.2, 26.7, $32.6 \%$, respectively).

Using transmission electron microscopy (TEM), we observed that mitochondria were of normal size with normal numbers in VSMC coming from the WKY group. In the SHR vehicle-treated group, VSMC showed hypertrophy with irregular nucleus, rich euchromatin, widening of perinuclear space, increased rough endoplasmic reticulum, and decreased pinocytosis vesicles and myofilament. Increased numbers and structural changes in mitochondria with severe swelling, extensive vacuolar degeneration, and lysis of cristae were also observed. Treatment of SHR with $60 \mu \mathrm{g} / \mathrm{kg}$ GCIP-27 ameliorated the ultramicrostructure of VSMC markedly, with the tissue looking nearly normal (Fig. 4). Although losartan and GCIP-27 $(7,20 \mu \mathrm{g} / \mathrm{kg})$ improved VSMC ultramicrostructure to some extent, there was still some injury seen, such as mild increased numbers and swelling of mitochondria.

Phospholipase C Activity PLC activity in the vehicle-
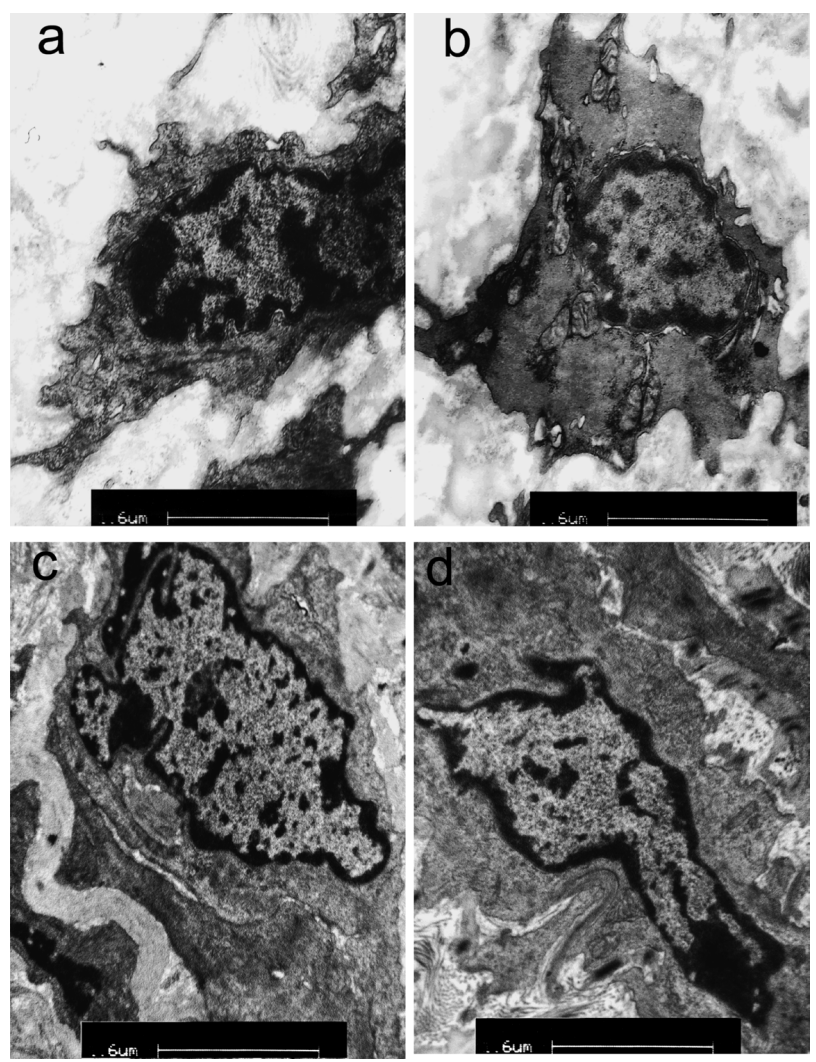

Fig. 4. Ultramicrostructure of Aorta under Transmission Electron Microscopy

Bar $=1.6 \mu \mathrm{m}$. (a) Wistar-Kyoto rats; (b) vehicle-treated spontaneously hypertensive rats (SHR); (c) losartan-treated SHR; (d) $60 \mu \mathrm{g} / \mathrm{kg}$ GCIP-27-treated SHR.

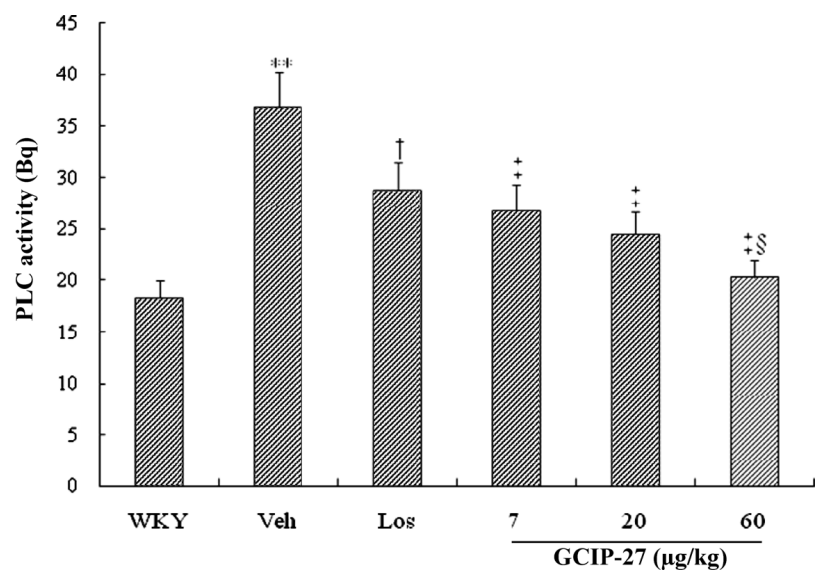

Fig. 5. Aortic Phospholipase C (PLC) Activity in Vehicle (Veh)-, Losartan (Los)- and GCIP-27-Treated Spontaneously Hypertensive Rats (SHR) and Wistar-Kyoto (WKY) Rats

Data are mean \pm S.E.M. $(n=5) . * * p<0.01 v$ s. WKY group; $\dagger p<0.05, \star p<0.01 v s$. Veh group; $\S p<0.01 v s$. Los group (one-way analysis of variance).

treated group was much higher than that in WKY rats. At all three doses tested, GCIP-27 inhibited PLC activity compared with vehicle control $(p<0.01)$ (Fig. 5). Losartan also showed a similar inhibitory effect on PLC activity, with a potency similar to that of $6 \mu \mathrm{g} / \mathrm{kg}$ GCIP-27.

\section{DISCUSSION}

Arteries are able to respond to physiological and patho- 
physiological stimuli to maintain adequate perfusion according to the metabolic demand of the tissue. ${ }^{25}$ VSMCs are one of the major constituents of blood vessel walls responsible for the maintenance of vessel structures and functions. Their hypertrophy, hyperplasia, and migration are considered key events in the development of atherosclerosis and other diseases. $^{26)}$ Accumulating evidence demonstrated that VSMC from SHR, which is frequently used as an animal model of genetic hypertension that tends to develop cardiovascular hypertrophy and remodeling with ageing, show exaggerated growth, with a higher specific growth rate, abnormal contact inhibition, and accelerated entry into the $\mathrm{S}$ phase of the cell cycle compared with cells from normotensive WKY rats. ${ }^{12,27)}$ In the present study, the proliferation activity, protein content, synthesis rate of DNA and protein, $\left[\mathrm{Ca}^{2+}\right]_{\mathrm{i}}$ in VSMC from SHR were significantly higher than those from WKY, consistent with the literature.

Although a variety of factors such as mechanical stress, neurohormonal factors, and growth factors are involved in the pathogensis of vascular remodeling, the $\mathrm{G}$ protein $\mathrm{Gq}$ is thought important in this process because various Gq-protein-coupled receptor ligands can trigger hypertrophy and hyperplasia responses in cultured VSMC and in vivo. ${ }^{25)}$ Therefore inhibition of Gq-protein signaling may be one approach to prevent vascular remodeling following pressure overload and other pathological stimuli. Measures targeted at the Gqprotein may inhibit multiple receptor signaling and may be more powerful against the development of vascular remodeling than using single receptor antagonists. Some efforts have been devoted to achieving this goal. For example, antisense $\mathrm{G} \alpha \mathrm{q} / 11$ oligonucleotides can block VSMC proliferation and proliferating cell nuclear antigen expression after stimulation of ET-1 in vitro. ${ }^{26)}$ The present work also found that GCIP27, a synthetic G $\alpha$ q-protein carboxyl terminus imitation polypeptide, effectively inhibited proliferation of VSMC and vascular remodeling in SHR. By comparison with vehicle group, treatment with GCIP-27 decreased SBP, thickness of aorta media, ratio of $\mathrm{MT} / \mathrm{LD}$, and collagen deposit as well as PLC activity significantly in SHR.

Even though hemodynamic forces alone are capable of inducing vascular remodeling and subsequent end-organ damage, blood pressure-independent mechanisms mediated by Ang II, NA, and ET-1, are also likely involved. ${ }^{28)}$ Rizzoni et $a l .{ }^{29)}$ demonstrated that cardiovascular remodeling of SHR appeared before the high blood pressure, and was not obviously related to the blood pressure level after hypertension onset. Therefore it may be important to reverse vascular remodeling to prevent and cure hypertension and its complications. ${ }^{30)}$ We found the antiremodeling effects of GCIP-27 were greater than that of losartan $(6 \mathrm{mg} / \mathrm{kg})$, although the hypotensive effect of losartan was more potent than that of GCIP-27 (even at the highest dose of $60 \mu \mathrm{g} / \mathrm{kg}$ used in the present study). At $60 \mu \mathrm{g} / \mathrm{kg}$, the hypotensive effect of GCIP27 was only $61.7 \%$ of losartan, whereas its effects on MT/LD ratio, collagen content and PLC activity were greater (by $10.4,21.7,103.2 \%$, respectively). These results suggest that, besides its hypotensive effect, GCIP-27 attenuates vascular remodeling through other pathways. As a synthetic peptide derived from the carboxyl terminus of G $\alpha \mathrm{q}$, GCIP-27 may inhibit proliferation and remodeling signaling by imitating $\mathrm{G} \alpha \mathrm{q}$ but without its signal transduction function.
Gq is a multifunctional protein that is best known to contribute to proliferation and differentiation of cells and contraction of blood vessels and the heart. As for blocking Gq signaling, side effects of GCIP-27 are of concerned. During the pathogenic process of cardiovascular remodeling, Gq signal is hyperfunctional and more powerful than that under normal states. Moreover, the cells are more sensitive to GCIP-27 in vascular remodeling than in the normal condition. ${ }^{14)}$ The present study showed that GCIP-27 had no significant effect on proliferation of 3T3 cell line even at an even high doses as high as $100 \mu \mathrm{g} / \mathrm{l}$.

While most Gq-coupled receptors such as $\alpha_{1}-\mathrm{AR}, \mathrm{AT}_{1}$ receptor, and $\mathrm{ET}_{\mathrm{A}}$ receptor, etc., induce vascular contraction, some other Gq-coupled receptors including bradykinin $\mathrm{B}_{2}$ receptor and muscarinic $\mathrm{M}_{3}$ receptor can induce vascular relaxation through production of nitric oxide and subsequent inhibition of cytoplasmic calcium release. ${ }^{31)}$ Taking these together, to block Gq signaling may cause unforeseen results. In the present study, nonetheless, GCIP-27 treatment decreased SBP and attenuated vascular remodeling.

In conclusion, the polypeptide drug GCIP-27 can suppress vascular remodeling effectively in vitro and in vivo, and the effect is superior to losartan, although the hypotensive effect of GCIP-27 is weaker than that of losartan. Therefore the antivascular remodeling effect of GCIP-27 in SHR is not entirely dependent on reduction of blood pressure, but also directly through Gq signaling pathway.

Acknowledgements This research was supported by Grants from National Key New Drug Development Project of China (2009ZX09103-052), the National Natural Science Foundation of China (No. 30973524) and Natural Science Foundation of Chongqing, China (No. CSTC2009AB5034).

\section{REFERENCES}

1) Erami C., Zhang H., Ho J. G., French D. M., Faber J. E., Am. J. Physiol. Heart Circ. Physiol., 283, H1577-H1587 (2002).

2) Wang X., Ohnishi M., Wada A., Tsutamoto T., Sawaki M., Fujii M., Matsumoto T., Yamamoto T., Kurokawa K., Yamada H., Kinoshita M., Life Sci., 69, 2477-2488 (2001).

3) Kuo L. E., Abe K., Zukowska Z., Peptides, 28, $435-440$ (2007).

4) Schiffrin E. L., Touyz R. M., Am. J. Physiol. Heart Circ. Physiol., 287, H435-H446 (2004)

5) Willianms B., Am. J. Cardiol., 87, 10C-17C (2001).

6) Zhang H., Cotecchia S., Thomas S. A., Tanoue A., Tsujimoto G., Faber J. E., Am. J. Physiol. Heart Circ. Physiol., 287, H2106-H2114 (2004).

7) Mitrovic V., Willenbrock R., Miric M., Seferovic P., Spinar J., Dabrowski M., Kiowski W., Marks D. S., Alegria E., Dukát A., Lenz K., Arens H. A., Am. Heart J., 145, E14 (2003).

8) Anderson L. L., Marshall G. R., Crocker E., Smith S. O., Baranski T. J., J. Biol. Chem., 280, 31019-31026 (2005).

9) Kostenis E., Martini L., Ellis J., Waldhoer M., Heydorn A., Rosenkilde M. M., Norregaard P. K., Jorgensen R., Whistler J. L., Milligan G., J. Pharmacol. Exp. Ther, 313, 78-87 (2005)

10) Lambright D. G., Sondek J., Bohm A., Skiba N. P., Hamm H. E., Sigler P. B., Nature (London), 379, 311-319 (1996).

11) Zhou J. Z., Li X. H., Zhang H. G., Tang Y., Wang X. Q., Acta Pharmacol. Sin., 24, 1108-1112 (2003).

12) Wang X. Q., Zhang H. G., Cheng Y. Q., Li X. H., Clin. Exp. Pharmacol. Physiol., 35, 1215-1221 (2008).

13) Yang D. L., Zhang H. G., Xu Y. L., Gao Y. H., Yang X. J., Hao X. Q., Su M., Wang X. Q., Li X. H., Biol. Pharm. Bull., 32, 376-381 (2009). 
14) Zhang H. G., Li X. H., Zhou J. Z., Liu Y., Jia Y., Yuan Z. B., Clin. Exp. Pharmacol. Physiol., 34, 1276-1281 (2007).

15) Kim Y. S., Ki M. S., Ha H., Park J., Kim H. J., Park K., Surg. Today, 32, 230-235 (2002)

16) Bunkenburg B., van Amelsvoort T., Rogg H., Wood J. M., Hypertension, 20, 746-754 (1992).

17) Lowry O. H., Rosebrough N. J., Farr A. L., Randall R. J., J. Biol. Chem., 193, 265-275 (1951).

18) Ling S. H., Dai A. Z., Guo Z. X., Yan X. J., Komesaroff P. A., Clin. Exp. Pharmacol. Physiol., 32, 571-578 (2005).

19) Zheng Y., Song H. J., Kim C. H., Kim H. S., Kim E. G., Sachinidis A., Ahn H. Y., J. Cardiovasc. Pharmacol., 43, 200-208 (2004).

20) Chu W. F., Sun H. L., Dong D. L., Qiao G. F., Yang B. F., Basic Clin Pharmacol. Toxicol., 98, 104-109 (2006).

21) Yao H. W., Zhu J. P., Zhao M. H., Lu Y., Respiration, 73, 236-242 (2006).

22) Yu J. X., Yin X. X., Shen J. P., Qiu J., Yin H. L., Jiang S. J., Clin. Exp. Pharmacol. Physiol., 33, 1231-1238 (2006).
23) Schnabel P., Gäs H., Nohr T., Camps M., Böhm M., J. Mol. Cell. Cardiol., 28, 2419-2427 (1996).

24) Schnabel P., Nohr T., Nickenig G., Paul M., Böhm M., Hypertension, 30, 1356-1361 (1997).

25) Belmadani S., Zerfaoui M., Boulares H. A., Palen D. I., Matrougui K., Am. J. Physiol. Heart Circ. Physiol., 295, H69-H76 (2008).

26) Li C., Xu Q., Cell. Signal., 12, 435-445 (2000).

27) Xiong C., Mou Y., Zhang J., Fu M., Chen Y. E., Akinbami M. A., Cui T., Life Sci., 77, 3037-3048 (2005).

28) Mervaala E. M., Müller D. N., Park J. K., Schmidt F., Löhn M., Breu V., Dragun D., Ganten D., Haller H., Luft F. C., Hypertension, 33, 389-395 (1999).

29) Rizzoni D., Castellano M., Porteri E., Bettoni G., Muiesan M. L., Agabiti-Rosei E., Am. J. Hypertens., 7, 193-200 (1994).

30) John St., Sutton M., Ferrari V. A., Curr. Treat. Options Cardiovasc. Med., 4, 97-108 (2002).

31) Vanhoutte P. M., Circ. J., 73, 595-601 (2009). 